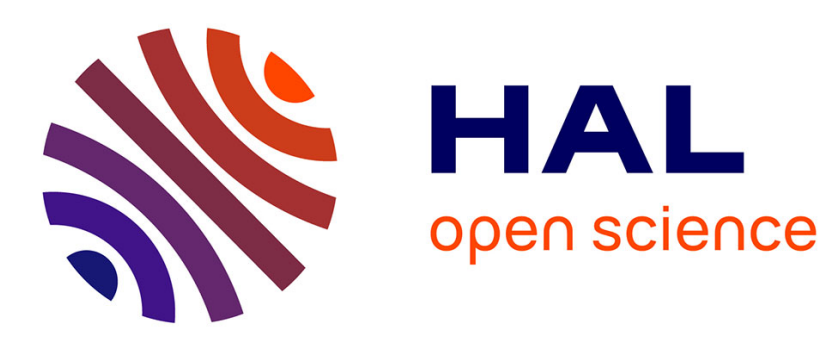

\title{
Modelling of joint effects on refractory lining behaviour
}

\author{
Alain Gasser, Kristin Terny-Rebeyrotte, Philippe Boisse
}

\section{To cite this version:}

Alain Gasser, Kristin Terny-Rebeyrotte, Philippe Boisse. Modelling of joint effects on refractory lining behaviour. Journal of Materials: Design and Applications, 2004, 218 (1), pp.19-28. $10.1177 / 146442070421800103$. hal-00020483

\section{HAL Id: hal-00020483 https://hal.science/hal-00020483}

Submitted on 19 Apr 2018

HAL is a multi-disciplinary open access archive for the deposit and dissemination of scientific research documents, whether they are published or not. The documents may come from teaching and research institutions in France or abroad, or from public or private research centers.
L'archive ouverte pluridisciplinaire HAL, est destinée au dépôt et à la diffusion de documents scientifiques de niveau recherche, publiés ou non, émanant des établissements d'enseignement et de recherche français ou étrangers, des laboratoires publics ou privés. 


\title{
Modelling of joint effects on refractory lining behaviour
}

\author{
A Gasser*, K Terny-Rebeyrotte and P Boisse \\ Laboratoire de Mécanique des Systèmes et des Procédés (UMR 8106 CNRS-ENSAM-ESEM), IPO-ESEM, France
}

\begin{abstract}
Expansion joints play an important role in refractory linings as they reduce stresses during heating. It is therefore necessary to take them into account in a mechanical analysis. In the case where the lining is a masonry construction (made up of bricks), it would require an excessive number of elements to model each brick and joint. The proposed solution is to replace the masonry with a material that has the same behaviour (or very near) as masonry. Since it is difficult to perform experimental tests on a set of bricks (to identify the parameters of the equivalent material), these loads were simulated on an elementary cell using a model developed at a local scale (scale of the components, bricks and joints). At this scale, the joints are represented as contacts (with normal and tangential behaviour). The parameters of a simplified equivalent material were obtained by an inverse identification. This model was validated by a thermomechanical test on a real structure.
\end{abstract}

Keywords: joint, refractory linings, multiscale approach, inverse identification, finite elements, thermo-mechanical analyses

\section{INTRODUCTION}

Refractory linings protect metallic structures from the hot products they contain, such as burning coal $\left(850^{\circ} \mathrm{C}\right)$ in coalfired power plants [1], or liquid steel $\left(1650^{\circ} \mathrm{C}\right.$ in steel ladles) in the steelmaking industry $[2,3]$. Owing to the difference in thermal expansion coefficient between steel and refractory materials, significant stresses appear in the refractory (during heating) that can lead to the failure of the linings. Finite element analyses of the global structure can assist a design that decreases these stresses [4-7]. In some cases, like the wear layer (which is in direct contact with the liquid steel) of a steel ladle, the refractory lining is made of brick masonry (Fig. 1). If this masonry is modelled as a continuum with the behaviour of brick material, the calculated stresses will be overestimated. Indeed, at the beginning of heating, the joints between bricks (Fig. 1) will close owing to thermal expansion, without the stress increasing. Therefore, it is very important to take these joints into account in the analysis.

Many studies have modelled the behaviour of masonry in civil engineering [8-12]. They use different homogeniation techniques, but almost all concern masonry with mortar between the bricks at room temperature. A few studies (references [13] and [14], for example) concern masonry containing joints without mortar. The aim is to develop a model for this type of masonry that can be used at high temperature.

Since using the finite element method would require an excessive number of elements to model each brick and each joint of the masonry (the number of bricks is too large), the approach developed in this study is to replace the masonry with a material that will have a behaviour equivalent to that of a set of bricks. To identify the parameters of this equivalent material, an approach using different scales (Fig. 2) was used. Indeed, to obtain the mechanical and thermal characteristics of the equivalent material, it is necessary to perform tests, at different temperatures, on masonry: compression, tension and shear, for example. However, these tests are very difficult to perform, particularly for temperatures different from room temperature, owing to the size and complexity of the masonry. Therefore, the idea is to simulate these different loads on a representative elementary cell with a model defined at a lower scale (called the local scale), that is, the scale of the elementary components (bricks and joints). The advantage of this approach is that only the behaviour of bricks and joints is necessary, and it is easier to perform tests on a brick or a joint than on a set of bricks. The model presented here is a first approach, in two dimensions, with a simplified equivalent material. 

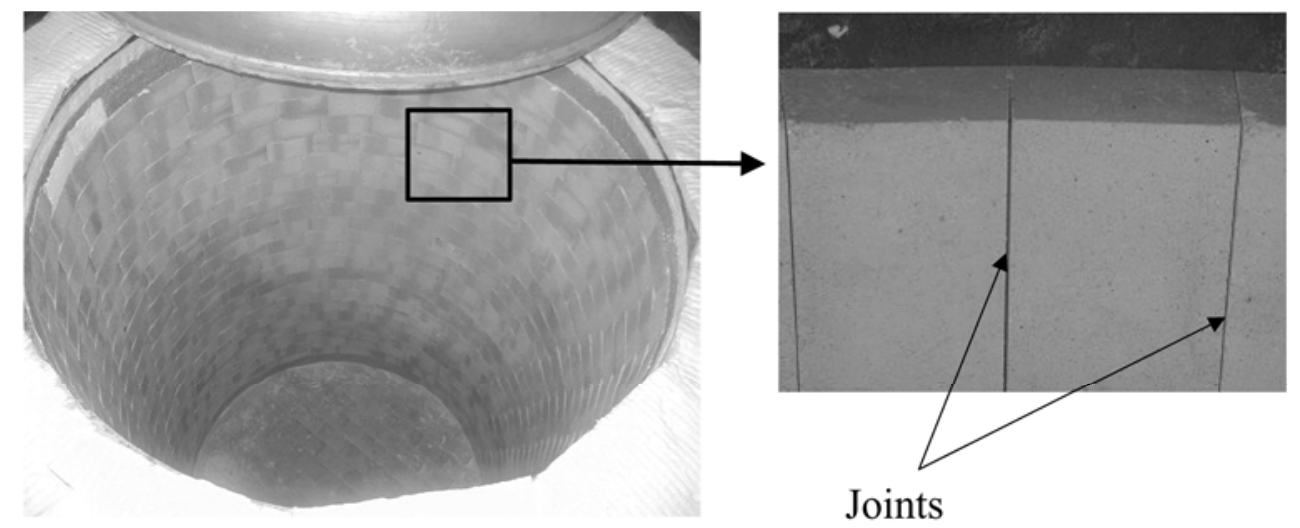

Fig. 1 Vessel containing refractory masonry (photos from the Sollac company)

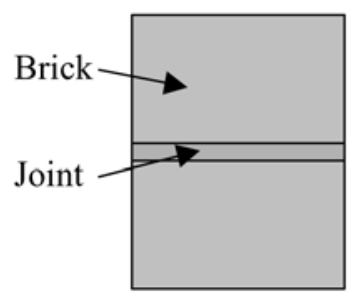

Scale of the components

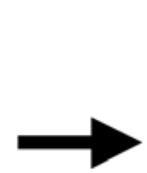

Scale of the elementary representative cell

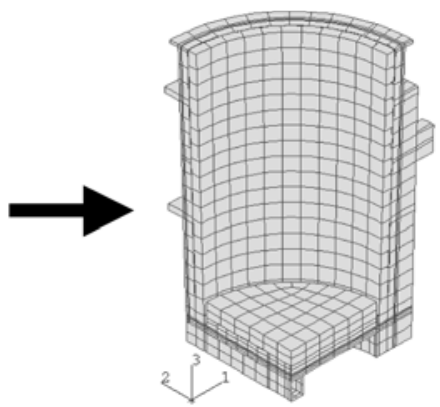

Scale of the structure (equivalent material)

Fig. 2 Different scales of the problem

\section{BEHAVIOUR MODELLING OF THE ELEMENTARY COMPONENTS}

The elementary components of masonry are bricks and joints. This section describes their modelling. The studied masonry is made up of fired bauxite bricks (section $200 \times 100 \mathrm{~mm}^{2}$.

\subsection{Brick behaviour}

As a first approach, for simplicity, the brick behaviour is assumed to be isotropic and linearly elastic. The mechanical parameters are obtained by a compression test. The parameters are: Young's modulus $7000 \mathrm{MPa}$; Poisson's ratio 0.2; coefficient of thermal expansion $7 \times 10^{-6} \mathrm{~K}^{-1}$.

\subsection{Joint behaviour}

The joints are modelled by a contact between two solids separated by a distance (clearance) corresponding to the thickness of a joint. For this model, it is necessary to obtain the joint thickness, the normal contact behaviour and the tangential contact behaviour (given by a Coulomb friction model).

\subsubsection{Tangential behaviour}

The tangential behaviour is given by a Coulomb friction model (verified experimentally). The friction coefficient is measured using two bricks put on an inclined plane which makes it possible to determine the initial angle of sliding. A friction coefficient of 0.75 is obtained for bauxite material.

\subsubsection{Normal behaviour}

The normal behaviour gives the evolution of contact pressure versus clearance between two bricks. This pressure is equal to zero when the distance is higher or equal to the joint thickness, and is maximum when the distance is zero. To obtain the complete law (between these two extreme values), a compression test was performed on two superposed bricks. The obtained force-displacement curve (Fig. 3) has two parts, the first (non-linear) corresponding to joint crushing, the second (linear) to brick stiffness.

It is possible to estimate the joint thickness with this curve by considering the intersection of the linear part (corresponding to the brick stiffness) with the abscissa axis (see Fig. 3). A value of $0.11 \mathrm{~mm}$ is obtained.

The normal contact law is identified using an inverse method. The principle is as follows. The load compression 


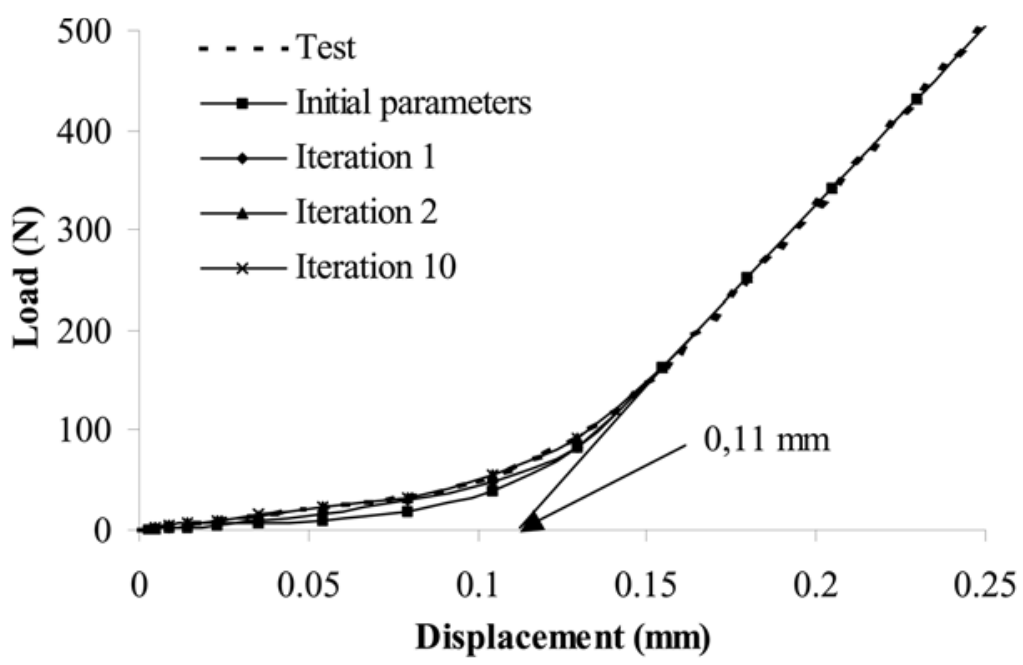

Fig. 3 Test/simulation comparison of compression between two bricks (with the different iterations of the inverse identification)

on two bricks in contact is simulated by finite elements using a normal contact law with initial parameters. An error between the experimental and simulated curves is defined. This error is minimized, and the parameters optimized, using the Levenberg-Marquardt optimization algorithm [15-18]. This method is iterative (Fig. 3). Table 1 shows the result of the inverse identification.

\subsubsection{Optical measurements}

The previous paragraph gives a global measure of the joint crushing. However, optical measurements (Fig. 4) can provide local information on this joint closure. Several images of the joint are taken with a camera at different moments of the compression loading on two bricks. A method of image correlation [19-21] allows the displacement field to be determined (Fig. 5a). The displacement difference between the two bricks at the joint level gives the joint crushing versus applied load. Figure 5b shows the result for measurements performed at three different points of the joint. The relative dispersion of the curves shows that joint crushing is not only due to roughness crushing but also to brick shape defects (lack of flatness or parallelism of the faces). Additionally, during building, some bricks are not perfectly placed in the masonry, leading to another origin of joint opening. All these defects must be taken into account in determining the initial joint thickness in real masonry without mortar.

Table 1 Normal contact law (contact pressure versus clearance between two bricks)

\begin{tabular}{ll}
\hline Clearance $(\mathrm{mm})$ & Pressure $(\mathrm{MPa})$ \\
\hline 0.11 & 0 \\
0.06 & 0.245 \\
0.03 & 0.373 \\
0.01 & 0.829 \\
0.002 & 1.086 \\
0 & 100 \\
\hline
\end{tabular}

\section{EQUIVALENT MECHANICAL MATERIAL BEHAVIOUR}

The aim of this section is to determine the mechanical characteristics of a material that will have an equivalent behaviour to masonry. For this, it is necessary to obtain the behaviour of a set of bricks, using the local model (of bricks and joints) described above.

\subsection{Load simulations on the elementary cell}

Using the joint and brick behaviour described in section 3 , it is possible to simulate the behaviour of a representative elementary cell (REC). This cell is shown in Fig. 6. It represents the periodicity of the structure and has no joints on its edges (otherwise the contact cannot be handled). Several loads are analysed:

(a) compressions in directions 1 and 2;

(b) shears in directions 1 and 2 under transverse compression;

(c) tension in direction 1 under transverse compression (tension in direction 2 is not analysed since the stiffness is zero).

Simulations of compression loads in directions 1 and 2 (Fig. 7) show that the behaviour is non-linear in the first step of joint closing, then becomes linear when the joints are closed. The two curves (in the compression direction) are different because there are twice as many joints in direction 2 than in direction 1.

A tension load can only be performed in direction 1 (in direction 2, the stiffness would be zero) when a compression load is applied previously in direction 2 (Fig. 8). Furthermore, the value of this transverse load has an important influence on the surface of the tension cycle (loading and unloading, Fig. 8b). The following can be observed: 


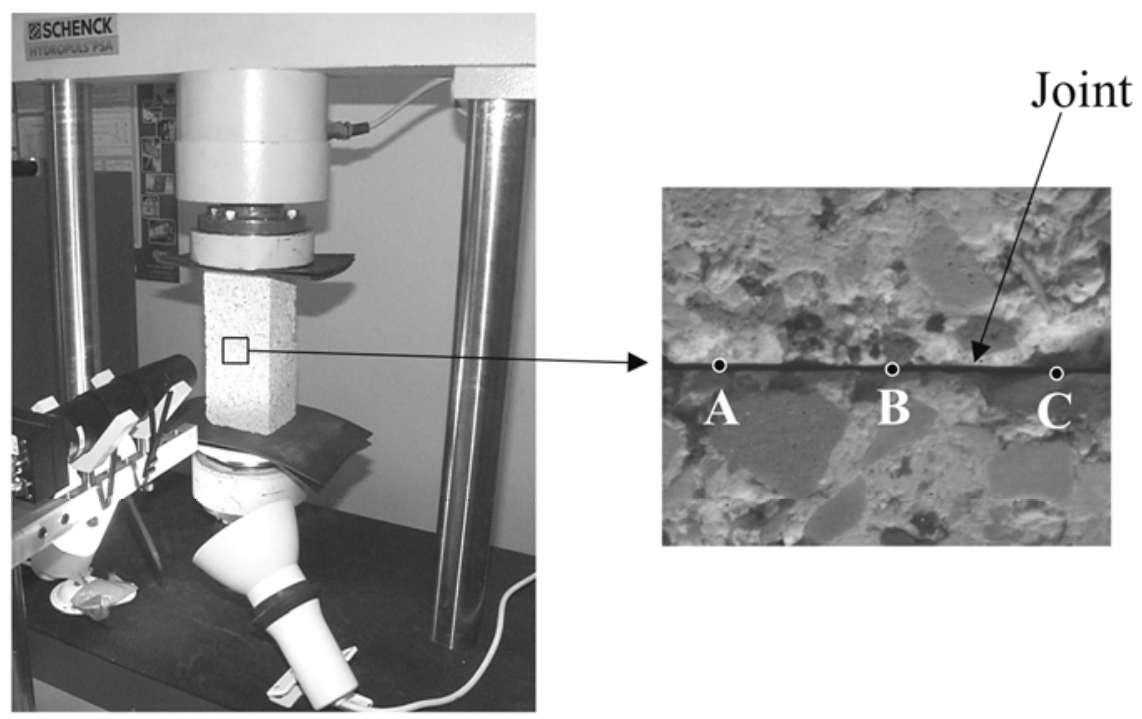

Fig. 4 Optical measurement device to determine the joint crushing during a compression test between two bricks

1. The first part of the cycle is approximately elastic, but with lower stiffness than the brick alone.

2. A second horizontal part corresponds to sliding between bricks (the beginning of sliding depends on the value of prescribed transverse displacement).

3. A third part corresponds to the beginning of unloading, with the arrest of sliding, and with the same stiffness as the first part.
4. A fourth part, also horizontal, corresponds once again to sliding (this fourth part is not symmetric with respect to the second part because the sliding begins at a different displacement owing to the different transverse forces (RF2, Fig. 8b) for loading and unloading).

The simulations of shear loads must also be performed under transverse compression. The shear load is obtained

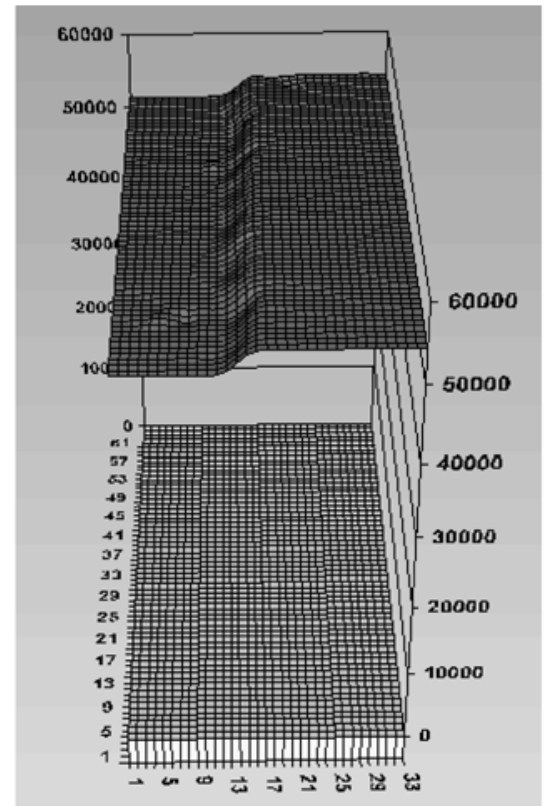

(a)

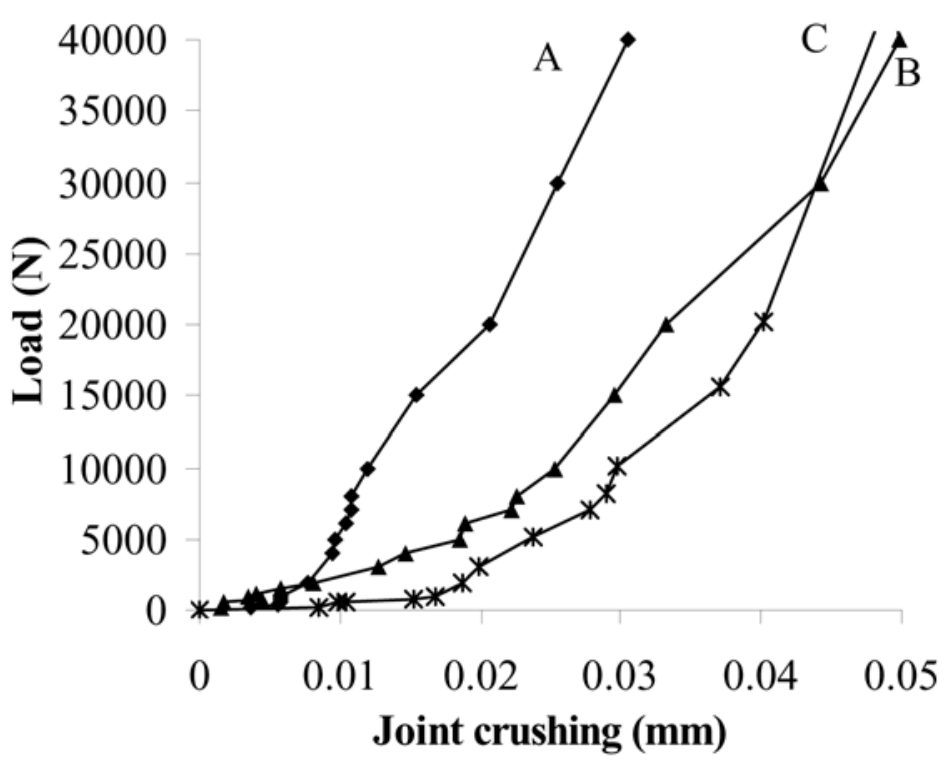

(b)

Fig. 5 Determination of joint crushing by the optical method: (a) displacement field (in pixels, vertical axis) versus $(x, y)$ position around the joint; (b) joint crushing (at three different points A, B and C, see Fig. 4) versus applied force 


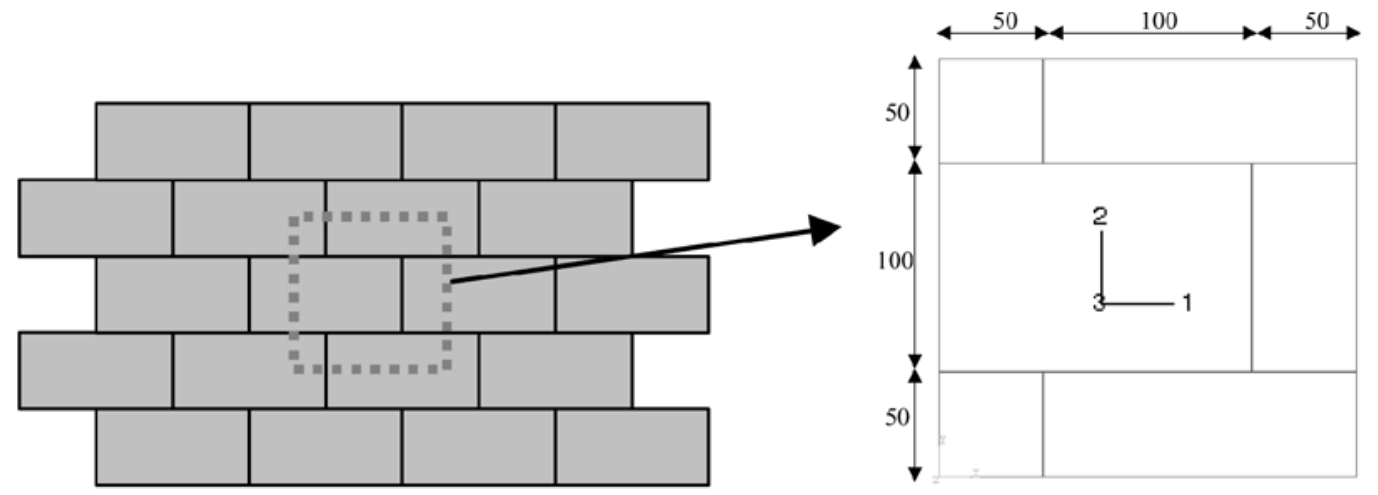

Fig. 6 Representative elementary cell

with one fixed face and prescribed displacements on the opposite face, in the direction of this same face. There are two possibilities: either in direction 1 (Fig. 9a) or in direction 2 (Fig. 10a). The results are different (Figs 9b and $10 \mathrm{~b}$ ) because it is the response of a structure and not the response of a simple material. Furthermore, initial stiffnesses for the same test with different transverse compression values are different. These two points will increase the difficulty of identification of a continuum equivalent material for which the shear modulus $G_{21}$ is necessarily equal to $G_{12}$. During these shear loads, one can observe a hysteresis due to sliding, as in tension (but smaller).

\subsection{Simplified equivalent material}

A first simplified equivalent material is proposed. An orthotropic, elastic and non-linear behaviour was chosen. Two simplifications are included:
1. Possible sliding between bricks (which is the origin of inelastic behaviour) is not taken into account.

2. Progressive joint closure is not considered. The joints are just open or closed.

In this case, the nine orthotropic coefficients depend on the state (open or closed) of the joints (in the following, open joints in direction 1 mean that joints perpendicular to direction 1 are open). Four cases must be considered:

(a) open joints in both directions;

(b) closed joints in both directions;

(c) open joints in direction 1 and closed joints in direction 2;

(d) open joints in direction 2 and closed joints in direction 1 .

The first two cases are the easier. When joints are open in both directions, stiffnesses are zero. When joints are closed in both directions, the stiffnesses are those of the bricks. On the other hand, for the two other cases (open joints in one direction, closed joints in the other), inverse identification of

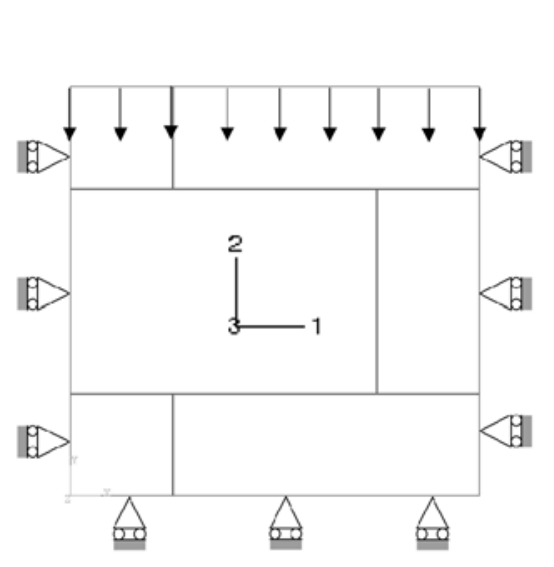

(a)

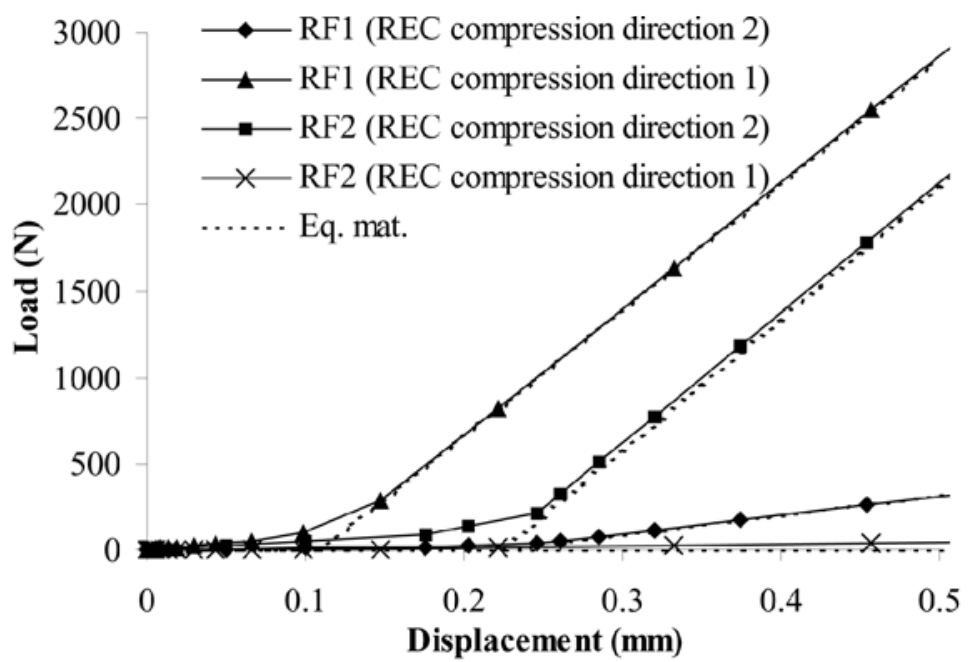

(b)

Fig. 7 (a) Boundary conditions for simulation of the compression load in direction 2 for the elementary cell; (b) comparison of the curves obtained with the elementary cell (REC) and with the equivalent material (Eq. mat.) for compression loads in the two principal directions (reaction forces RF1 and RF2 in directions 1 and 2, respectively, versus prescribed displacement $u_{1}$ or $u_{2}$ ) 


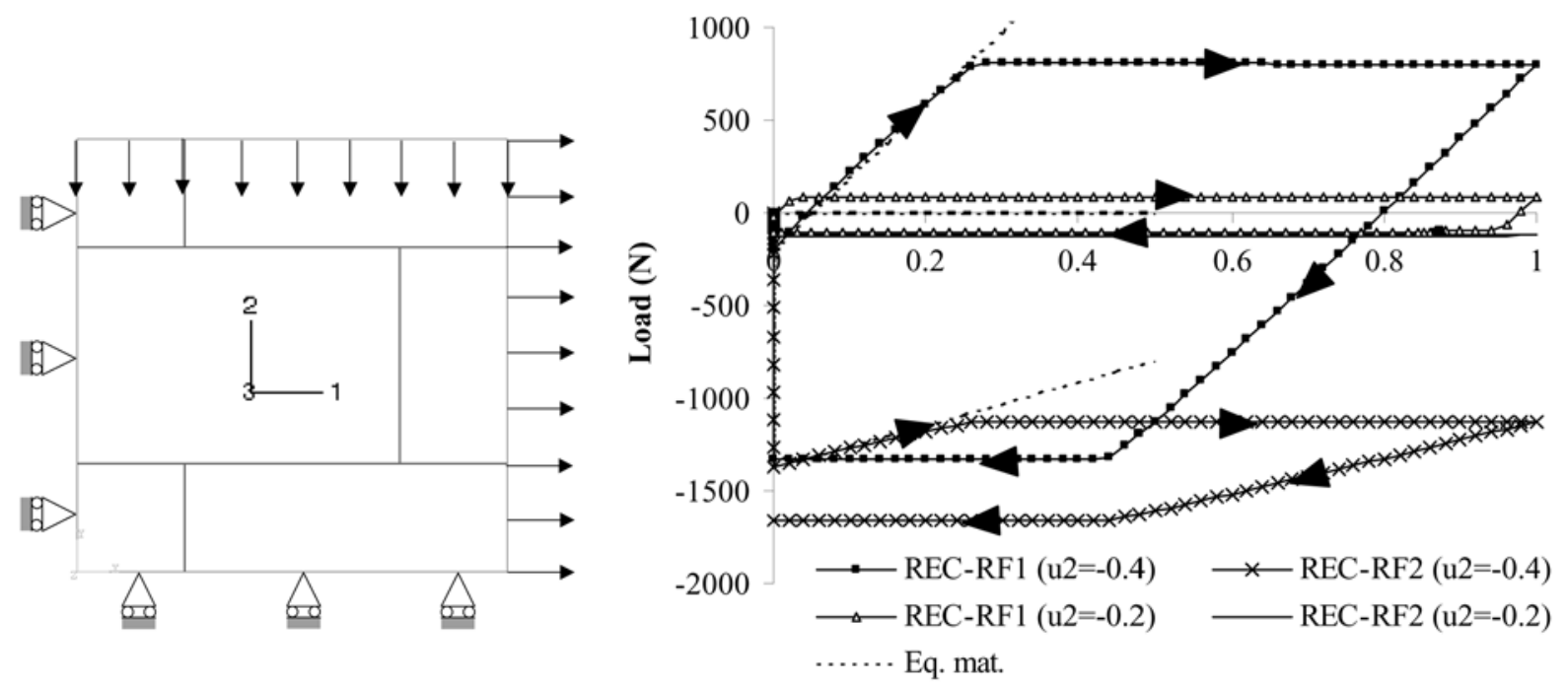

Displacement $\mathbf{u}_{1}(\mathrm{~mm})$

(a)

(b)

Fig. 8 Tension load in direction 1 (under transverse compression): (a) boundary conditions for the simulation on the elementary cell; (b) comparison of the curves obtained with the elementary cell (REC) and with the equivalent material (Eq. mat.) for two different values of transverse compression $u_{2}$ of 0.2 and $0.4 \mathrm{~mm}$ (RF1 and RF2 are the reaction forces in directions 1 and 2 respectively)

the mechanical characteristics is performed with the help of compression, tension and shear (under transverse compression) loads on the elementary cell (presented in section 3.1). It must be noted that the shear modulus $G_{12}$, is a mean value chosen independently of the 'shear direction' or transverse compression value (this is an approximation due to the simplicity of the model, i.e. a continuum material). The thermal and thermomechanical coefficients (conductivity,
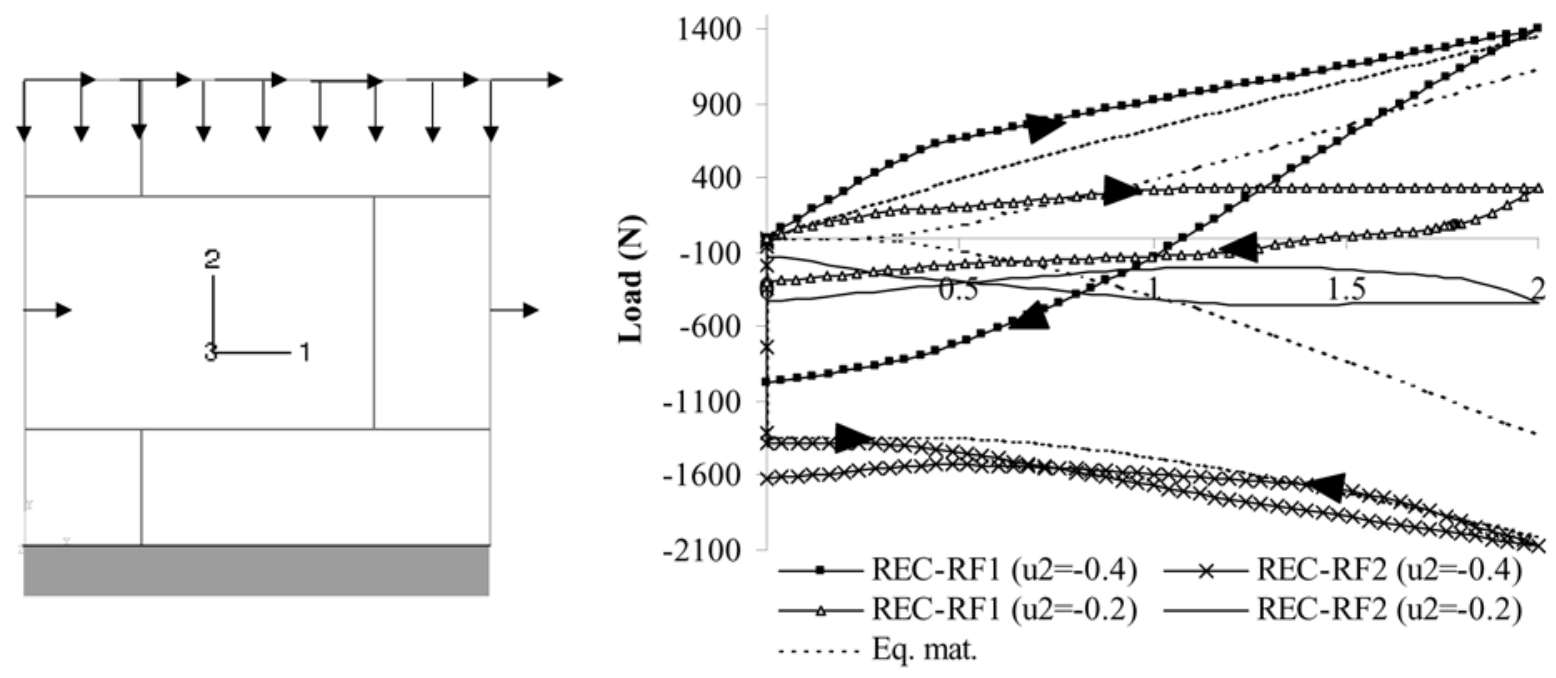

Displacement $u_{1}(\mathrm{~mm})$

(a)

(b)

Fig. 9 Shear load in direction 1 (under transverse compression): (a) boundary conditions for the simulation on the elementary cell; (b) comparison of the curves obtained with the elementary cell (REC) and with the equivalent material (Eq. mat.) for two different values of transverse compression $u_{2}$ of 0.2 and $0.4 \mathrm{~mm}$ (RF1 and RF2 are the reaction forces in directions 1 and 2 respectively) 


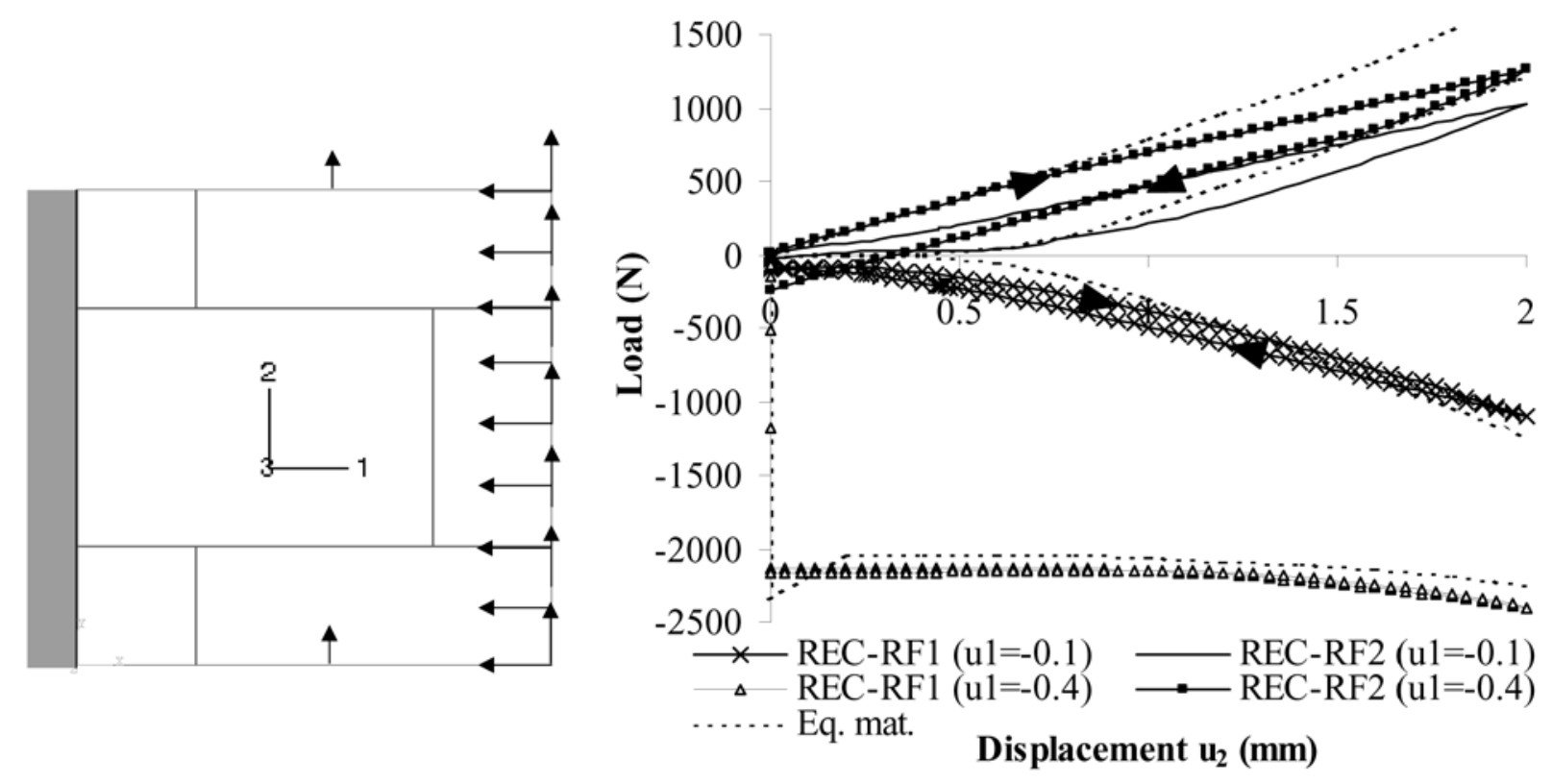

(a)

(b)

Fig. 10 Shear load in direction 2 (under transverse compression): (a) boundary conditions for the simulation on the elementary cell; (b) comparison of the curves obtained with the elementary cell (REC) and with the equivalent material (Eq. mat.) for two different values of transverse compression $u_{1}$ of 0.1 and $0.4 \mathrm{~mm}$ (RF1 and RF2 are the reaction forces in directions 1 and 2 respectively)

specific heat, thermal expansion) are taken, in a first approximation, to be equal to those of bricks.

The final results are given in Table 2. Since zero values for the Young's and shear moduli are not accepted for a finite element analysis, they are replaced with a very small value (1 MPa).

To determine if a joint is open or closed, a stress criterion is used. In direction 2, owing to the fact that the joints cut the entire length of the elementary cell, the stress necessary to close these joints, $\sigma_{2}$, is independent of the joint state in direction 1 . On the other hand, the stress necessary to close the joints in direction 1 depends on the joint state in direction 2. This stress is denoted by $\sigma_{1}^{o}$ when joints are open in direction 2 , and by $\sigma_{1}^{c}$ when they are closed.

Table 2 Elastic characteristics (in plane 12) of the simplified equivalent material for joint opening or closing in both directions

\begin{tabular}{lll}
\hline & $\begin{array}{l}\text { Open joints } \\
\text { (direction 1) }\end{array}$ & $\begin{array}{l}\text { Closed joints } \\
\text { (direction 1) }\end{array}$ \\
\hline Open joints (direction 2) & $E_{1}=0 \mathrm{MPa}$ & $\begin{array}{l}E_{1}=7000 \mathrm{MPa} \\
E_{2}=0 \mathrm{MPa}\end{array}$ \\
& $E_{12}=0$ & $\mathrm{MPa}$ \\
& $G_{12}=0.2$ \\
& & $G_{12}=1000 \mathrm{MPa}$ \\
Closed joints (direction 2) & $E_{1}=3700 \mathrm{MPa}$ & $E_{1}=7000 \mathrm{MPa}$ \\
& $E_{2}=7000 \mathrm{MPa}$ & $E_{2}=7000 \mathrm{MPa}$ \\
& $v_{12}=0.11$ & $v_{12}=0.2$ \\
& $G_{12}=1000 \mathrm{MPa}$ & $G_{12}=2900 \mathrm{MPa}$ \\
\hline
\end{tabular}

The values of these different stress thresholds are determined by the inverse method applied on two compression loads, using the slope changes of the transverse behaviour curves in both directions (see Fig. 11). The obtained values are $\sigma_{1}^{o}=-5.5 \times 10^{-4} \mathrm{MPa}, \sigma_{1}^{c}=-5 \mathrm{MPa}$ and $\sigma_{2}=-1.1 \times$ $10^{-3} \mathrm{MPa}$.

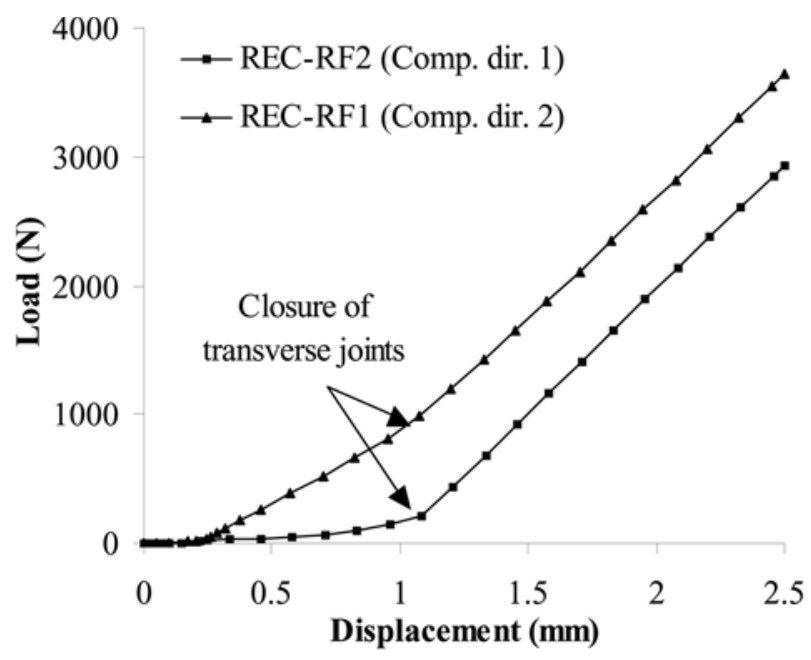

Fig. 11 Transverse behaviour during compression loads in directions 1 and 2 (elementary cell), with determination of transverse joint closure (RF1 and RF2 are the reaction forces in directions 1 and 2 respectively) 


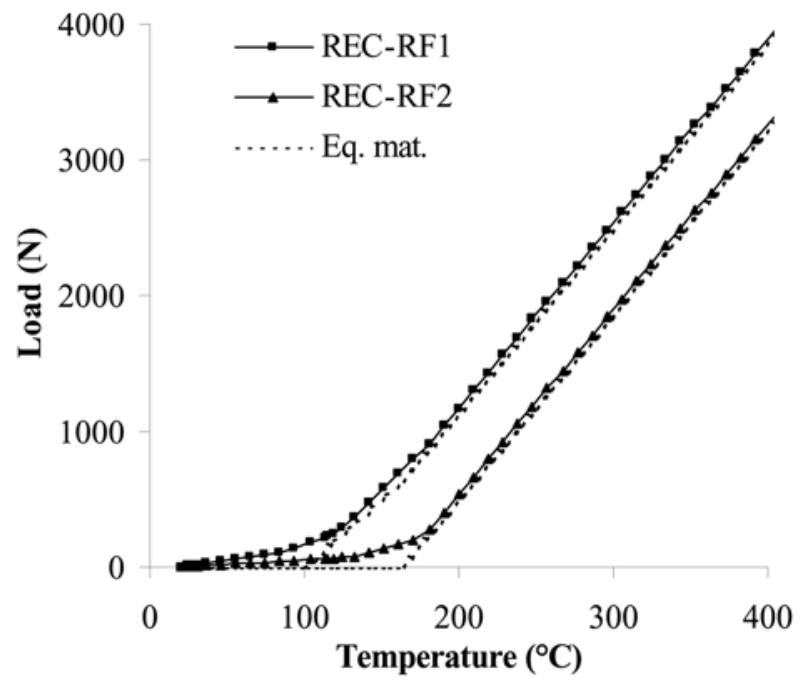

Fig. 12 Thermal load (uniform temperature applied on entire cell with fixed edges): comparison of the curves obtained on the elementary cell (REC) and with the equivalent material (Eq. mat.) (RF1 and RF2 are the reaction forces in directions 1 and 2 respectively).

The simulations of compression, tension and shear loads with this simplified model allow an appreciation of its domain of validity. The compression simulations in both principal directions (Fig. 7) show a good agreement with the curves obtained on the elementary cell. The only difference is located in the first non-linear part which is not reproduced by the equivalent material, because the joints are either open or closed, without intermediate cases.

As regards tension load simulations (Fig. 8), the model only predicts the first linear part corresponding to a step without sliding. This represents a limit of validity of the model. The shear simulations (Figs 9 and 10) show that the model gives a result that is not too far from the elementary cell despite a relative dispersion of the curves obtained on this elementary cell.

Since this model will be used to simulate temperature effects, a thermal load was then simulated on the elementary cell, and with the equivalent material. It is a uniform temperature load that evolves from 20 to $400^{\circ} \mathrm{C}$, applied on the elementary cell with fixed edges. Comparison of force evolution on the edges, in both directions, shows a good agreement of the simplified model with respect to the elementary cell results (Fig. 12).

\section{VALIDATION}

\subsection{Thermomechanical test}

A thermomechanical experimental test was conducted by the Sollac company [22] (Fig. 1). It concerns a cylindrical metallic structure (diameter $2 \mathrm{~m}$, thickness $30 \mathrm{~mm}$ ) with a flat bottom covered by masonry (fired bauxite bricks) (see Fig. 13). The metallic structure and masonry are separated

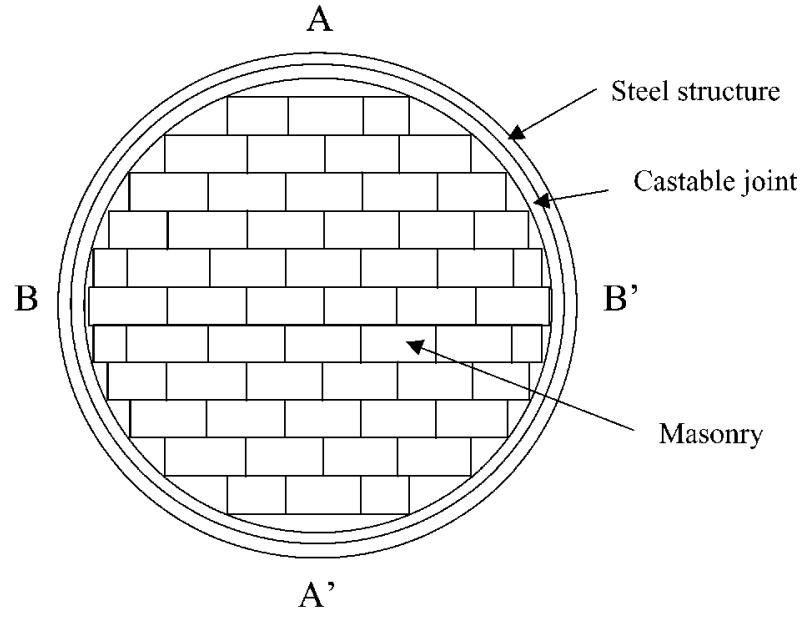

Fig. 13 Drawing of the plane masonry

by a castable joint $30 \mathrm{~mm}$ thick. This structure represents, with a little simplification, the bottom of a ladle in the steelmaking industry. The top of the flat masonry is submitted to a uniform thermal loading $\left(50^{\circ} \mathrm{C} / \mathrm{h}\right)$ up to $1500^{\circ} \mathrm{C}$. The metallic structure is cooled to $20^{\circ} \mathrm{C}$ outside. Strain gauges, fixed to the external face of the metallic structure at points $\mathrm{A}, \mathrm{A}^{\prime}, \mathrm{B}$ and $\mathrm{B}^{\prime}$, make it possible to determine the hoop stresses (Fig. 14). Anisotropy of the results in both directions can be observed.

\subsection{Simulation}

The above test was simulated in two dimensions (with plane stresses), replacing the masonry with the simplified equivalent material. Only one-quarter of the structure was studied

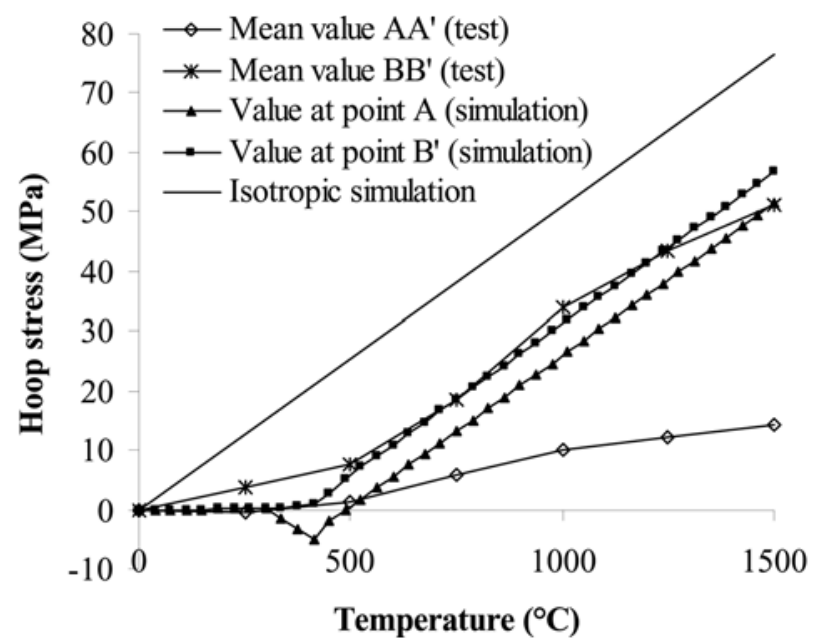

Fig. 14 Hoop stresses on the external face of the steel structure: experimental mean values (at points $\mathrm{AA}^{\prime}$ and $\mathrm{BB}^{\prime}$ ), numerical values at points $\mathrm{A}$ and $\mathrm{B}^{\prime}$ (simulation with the equivalent material) and isotropic simulation (without joints) 
(owing to symmetry). For simplification, the steel, castable joint and masonry are perfectly linked.

Two problems appear in this very simplified analysis:

1. What temperature field must be prescribed in two dimensions while the real field is three-dimensional (the temperature is not constant through the brick thickness)?

2. How to take into account the fact that some voids remain between the masonry and the castable joint (see Fig. 13) owing to the rectangular brick shape, while the equivalent material is completely in contact with this joint?

The steady-state temperature field that was chosen is the one at the top of the bricks (which seems to be the best two-dimensional field, see the three-dimensional simulations of ladles in reference [7] with real thermal loading and heat transfer): a temperature of $1500^{\circ} \mathrm{C}$ is prescribed on the masonry and the castable joint, and $20^{\circ} \mathrm{C}$ on the external face of the steel structure (so the temperature decreases linearly through the thickness of the steel).

The voids between the bricks and the castable joint were taken into account in giving a very soft behaviour to the castable material. Its Young's modulus (30 MPa) was determined so that an isotropic simulation (linear isotropic behaviour of the equivalent material) gives the stiffness of the test (see Fig. 14).

The simulation performed with the equivalent material (Fig. 14) predicts some experimental results:

(a) a stress level lower than that for an isotropic simulation (with brick behaviour, without joints) showing the influence of the joints;

(b) an anisotropic behaviour between directions 1 and 2 owing to there being twice as many joints in direction $\mathrm{AA}^{\prime}$ as in direction $\mathrm{BB}^{\prime}$.

The difference observed between numerical and experimental curves at point A may be explained by the simplicity of the numerical analysis (in two dimensions), and also by the elastic behaviour taken for the brick material (which becomes viscoelastic for high temperatures).

\section{CONCLUSIONS}

To take into account the effect of joints in refractory masonries, the masonry is replaced, in a finite element analysis, with an equivalent material. A first simplified model in two dimensions was presented. The material behaviour is orthotropic, elastic and non-linear, depending on joint opening or closure. Its parameters were identified, by an inverse method, from different loads simulated with the help of a component model (bricks and joints). This first multiscale approach was validated by a thermomechanical test on a structure containing flat masonry.

The advantage of this simplified model is that it can be easily used in industrial conditions, and gives relatively accurate results in the case of only slight sliding between bricks.
In the future, the model will be improved and extended in the following directions:

(a) three-dimensional modelling;

(b) progressive closure of joints (progressive evolution of Young's modulus versus strains);

(c) consideration of sliding (which can be modelled by a perfect plastic behaviour);

(d) cylindrical masonries (not flat);

(e) application to a real structure, such as a steel ladle (with flat and cylindrical masonries).

\section{ACKNOWLEDGEMENT}

The authors acknowledge the support provided by Arcelor company (Sollac Dunkerque).

\section{REFERENCES}

1 Gordon, E. D. Refractories in CFB applications. 12th International Conference on Fluidized Bed Combustions, San Diego, California, 1993, pp. 967-983.

2 Poirier, J. Recent tendencies in refractories in relation to service in the steel industry. 39th Colloquium on Refractories, Aachen, Germany, 1996, pp. 6-16.

3 Peruzzi, S., Poirier, J., Glandus, J. C. and Huger, M. Numerical study of the in-service behaviour of refractory parts used in continuous casting. 6th European Ceramic Society Conference, Brighton, UK, 1999, pp. 161-162.

4 Lee, H. P. Thermal stress analyses of a waste storage container. Computers and Struct., 1996, 61(2), 197-224.

5 Stuart, R., Shipley, L., Ghose, A. and Hiremath, M. Thermal degradation of the concrete roof of high-level waste storage tank. Computers and Struct., 1997, 64(5-6), 959-972.

6 Hernandez, J. F., Schmitt, N., Meunier, P. and Poirier, J. Thermomechanical computations of refractory structure. Improvement due to the modelling of the dehydration process in high alumina castable. UNITECR'99, Berlin, Germany, 1999, pp. 107-109.

7 Derré, V., Gasser, A. and Boisse, P. Poches à acier 270 tonnes à tenue améliorée. Usinor/LMSP report, Orléans, France, 2000.

8 Anthoine, A. Derivation of the in-plane elastic characteristics of masonry through homogenization theory. Int. J. Solids and Struct., 1995, 32(2), 137-163.

9 Pegon, P. and Anthoine, A. Numerical strategies for solving continuum damage problems with softening: application to the homogenization of masonry. Computers and Struct., 1997, 64(1-4), 623-642.

10 Cecchi, A. and Di Marco, R. Homogenization of masonry walls with a computational oriented procedure. Rigid or elastic block? Eur. J. Mechanics-A/Solids, 2000, 19(3), 535-546.

11 Ma, G., Hao, H. and Lu, Y. Homogenization of masonry using numerical simulations. J. Engng Mechanics, 2001, 127(5), 421-431.

12 Zucchini, A. and Lourenco, P. B. A micro-mechanical model for the homogenisation of masonry. Int. J. Solids and Struct., 2002, 39(12), 3233-3255. 
13 Takahasi, K., Miyamoto, Y. and Kumagai, M. Thermomechanical stress analysis in brick linings by FEM using nonlinear boundary condition. UNITECR'97, New Orleans, Louisiana, 1997, pp. 349-357.

14 Andreev, K. and Harmuth, H. Modelling of the thermomechanical behaviour of the lining material of teeming ladles. UNITECR'01, Cancun, Mexico, 2001, CDROM.

15 Levenberg, K. A method for the solution of certain nonlinear problems in least squares. Q. Appl. Math., 1944, 2, $164-168$.

16 Marquardt, D. W. An algorithm for least squares estimation of nonlinear parameters. J. Soc. Ind. Appl. Math., 1963, 11(2), $431-441$.

17 Schnur, D. S. and Zabaras, N. An inverse method for determining elastic material properties and a material interface. Int. J. for Numer. Meth. in Engng, 1992, 33, 2039-2057.
18 Gasser, A., Boisse, P., Dutheillet, Y. and Poirier, J. Experimental and numerical analyses of thermomechanical refractory lining behaviour. Proc. Instn Mech. Engrs, Part L: J. Materials: Design and Applications, 2001, 245, 41-54.

19 Sutton, M., Wolters, W. J., Peters, W. H., Ranson, W. F. and McNeill, S. R. Determination of displacements using an improved digital correlation method. Image and Vision Computing, 1983, 1-3, 133-139.

20 Vacher, P., Dumoulin, S. and Arrieux, R. Determination of the forming limit diagram from local measurement using digital image analysis. Int. J. Forming Processes, 1999, 2(3-4), 395-408.

21 Dumont, F., Hivet, G., Rotinat, R., Launay, J., Boisse, P. and Vacher, P. Mesures de champ pour des essais de cisaillement sur des renforts tissés. Mécanique et Industrie, 2003, 4(6), 627-635.

22 Themines, D. Comportement des maçonneries. Sollac report, Dunkerque, France, 1994. 